\title{
A double source heat pump: a case study
}

\section{Angelo Zarrella Diego Guzzon Giuseppe Emmi}

\author{
Roberto Zecchin \\ Michael Ciantia
}

\author{
Philippe Pasquier \\ Michele De Carli
}

\begin{abstract}
The design of a Ground Source Heat Pump (GSHP) system is critical because design choices affect the system's energy performance and operating conditions. If the thermal load profile on the ground side is unbalanced the ground temperature will change throughout the time and, consequently, also the energy efficiency of the heat pump. This phenomenon is known as "ground thermal drift". A possible solution to avoid this inconvenience is the adoption of a bybrid system.

In this work a double source heat pump is investigated, i.e. the heat pump can use air or ground as heat source or heat sink. The case study is an office building located in the city of Padova (Italy). The building load profile is cooling dominant and a thermal drift can be observed in the monitoring records. A new water-to-water heat pump coupled to the boreholes and also to an air-cooled condenser was recently installed in order to tackle the thermal drift of the ground.
\end{abstract}

Detailed computer simulations of the system were carried out via EnergyPlus software to investigate the energy performance of the system and the control strategy for switching between the heat sources (air or ground). The study shows the advantages of the double source heat pump.

\section{INTRODUCTION}

Ground source heat pump (GSHP) systems are an attractive as well as a promising and worldwide used technology for space heating and cooling of buildings (Bayer et al., 2012). The primary advantage of these systems is the use of the ground or groundwater as the heat source-sink for the heat pump instead of the outside air (Michopoulos et al., 2007). The main disadvantage of GSHP systems, compared to conventional ones, is surely the higher initial costs due to drilling for ground heat exchangers or groundwater wells.

An important aspect to consider is that the energy efficiency of heat pumps fully depends on the temperatures of the secondary heat-carrier fluids on the condenser and evaporator sides. The temperatures on the building side in the heating and cooling modes are usually fixed or controlled, whereas the temperature of the external heat-carrier fluid, in the case of borehole heat exchangers depends on the ground thermal-physical properties and temperature as well as on the annual ground load profile and the borehole field layout. In fact, if the annual amount of heat extracted from the ground in the heating mode is higher (lower) than that injected into it in the cooling mode, the long-term

Angelo Zarrella (angelo.zarrella@unipd.it) is Assistant Professor of Energy Science at University of Padua. Roberto Zecchin (roberto.zecchin@unipd.it) is former Professor of Thermal Systems at University of Padua and partner at Manens-Tifs S.p.A. Philippe Pasquier (philippe.pasquier@polymtl.ca) is Professor of Hydrogeology at Polytechnique Montréal. Diego Guzzon (dguzzon@manens-tifs.it) and Michael Ciantia (mciantia@manens-tifs.it) are mechanical engineers at Manens-Tifs S.p.A. Michele De Carli (michele.decarli@unipd.it) is Associate Professor of Energy Buildings at University of Padua. Giuseppe Emmi (giuseppe.emmi@unipd.it) is Research Assistant at University of Padua. 
ground temperature decreases (increases). This behaviour is well-known as thermal drift of the ground and affects the system's energy efficiency. Hybrid GSHP systems can help to reduce this disadvantage since the annual load profile on the ground can be balanced through an auxiliary system, e.g. a cooling tower or an air-to-water chiller in cooling and a gas boiler or solar thermal collectors in heating mode. Moreover, the hybrid systems can also reduce the initial investment. Recently, a double source heat pump for heating, cooling and domestic hot water production was investigated in the framework of a H2020 European project named Geot€ch (2018); in this case, the control system of the heat pump selects the most favourable source or sink between air or ground. Ruiz-Calvo et al. (2017) and Corberán et al. (2018) analysed the thermal performance of that dual source heat pump in an office building in the Netherlands.

In this work a retrofit of an existing ground source heat pump is analysed. The retrofitted system consists of a new heat pump coupled with both the ground, by means of the existing borehole heat exchangers, and an aircondenser used during the cooling season. A simulation model, tuned on eleven years of monitoring of the previous system, was used to carry out multi-year integrated simulations in order to evaluate the long-term thermal behaviour of the entire system and investigate the control strategy of the air-condenser.

\section{METHOD}

The computer simulations were carried out by means of the well-known energy simulation program EnergyPlus (U.S. Department Of Energy, 2016). Through this tool a detailed modelling of the building and the plant-system is possible. The borehole heat exchangers (BHEs) are simulated via the well-known $\mathrm{g}$-functions approach (Eskilson, 1987). Given the dimensionless nature of the $\mathrm{g}$-function, it is possible to precompute the transfer function and apply it to various $\mathrm{BHE}$ configurations and ground thermal properties. Once constructed, the g-function of the BHE is convoluted with the incremental heat flux signal to obtain the mean fluid temperature in accordance with the equation below:

$$
T_{f}(\tau)=T_{g}+q(\tau) \cdot R_{b}+\sum_{i=1}^{n}\left(\frac{q_{i}-q_{i-1}}{2 \pi \cdot \lambda} \cdot g\left(\frac{\tau-\tau_{i-1}}{\tau_{s}}, \frac{r_{b}}{L_{b}}\right)\right)
$$

where $\tau_{s}=L_{b}^{2} /\left(9 a_{g}\right)$ is the characteristic time.

Eskilson's original work considered the situation of a uniform temperature along the borehole wall that was the same for all the boreholes present in the field. To explain the influence of the boundary conditions on early time steps, Eskilson proposed using a constant heat extraction-injection rate on the time-scale below:

$$
\tau=\frac{5 r_{b}^{2}}{a_{g}}
$$

This time step for a typical borehole turns out to be between 2 to 6 hours.

At each time step, the energy efficiency of the heat pump can be calculated using the following equations; in the cooling mode:

$$
\begin{aligned}
& \frac{Q_{c}}{Q_{c, n o m}}=A_{1}+A_{2} \cdot\left(\frac{T_{L, i n}}{T_{r e f}}\right)+A_{3} \cdot\left(\frac{T_{S, i n}}{T_{r e f}}\right)+A_{4} \cdot\left(\frac{\dot{V}_{L}}{\dot{V}_{\text {nom }}}\right)+A_{5} \cdot\left(\frac{\dot{V}_{S}}{V_{\text {nom }}}\right) \\
& \frac{P_{\text {elc }}}{P_{\text {el } c, n o m}}=B_{1}+B_{2} \cdot\left(\frac{T_{L, i n}}{T_{r e f}}\right)+B_{3} \cdot\left(\frac{T_{S, i n}}{T_{r e f}}\right)+B_{4} \cdot\left(\frac{\dot{V}_{L}}{\dot{V}_{\text {nom }}}\right)+B_{5} \cdot\left(\frac{\dot{V}_{S}}{\dot{V}_{\text {nom }}}\right)
\end{aligned}
$$


in the heating mode:

$$
\begin{aligned}
& \frac{Q_{h}}{Q_{h, n o m}}=C_{1}+C_{2} \cdot\left(\frac{T_{L, i n}}{T_{r e f}}\right)+C_{3} \cdot\left(\frac{T_{S, i n}}{T_{r e f}}\right)+C_{4} \cdot\left(\frac{\dot{V}_{L}}{\dot{V}_{\text {nom }}}\right)+C_{5} \cdot\left(\frac{\dot{V}_{S}}{\dot{V}_{\text {nom }}}\right) \\
& \frac{P_{\text {el }}}{P_{\text {el h, nom }}}=D_{1}+D_{2} \cdot\left(\frac{T_{L, i n}}{T_{\text {ref }}}\right)+D_{3} \cdot\left(\frac{T_{S, i n}}{T_{r e f}}\right)+D_{4} \cdot\left(\frac{\dot{V}_{L}}{\dot{V}_{\text {nom }}}\right)+D_{5} \cdot\left(\frac{\dot{V} S}{\dot{V}_{\text {nom }}}\right)
\end{aligned}
$$

where $T_{\text {ref }}$ is a fixed value equal to $283.15 \mathrm{~K}$.

The model of the heat pump when it operates with the air-condenser is implemented in the energy model by the following three equations: chiller capacity as function of leaving chilled fluid temperature and entering condenser air temperature $\left(Q_{c, \text { FTemp }}\right)$, the ratio of electric power and cooling capacity $\left(E I R_{\text {FTemp }}\right)$ as function of leaving chilled fluid temperature and entering condenser air temperature, EIR FPLR function of partial load ratio (PLR).

$$
\begin{aligned}
& \frac{Q_{c}}{Q_{c, \text { nom }}}=a+b \cdot T_{c f, l}+c \cdot T_{c f, l}^{2}+d \cdot T_{c o n d, e}+e \cdot T_{c o n d, e}^{2}+f \cdot T_{c f, l} \cdot T_{c o n d, e} \\
& E_{\text {ITemp }}=a+b \cdot T_{c f, l}+c \cdot T_{c f, l}^{2}+d \cdot T_{c o n d, e}+e \cdot T_{c o n d, e}^{2}+f \cdot T_{c f, l} \cdot T_{c o n d, e} \\
& \operatorname{EIR}_{F P L R}=a+b \cdot P L R+c \cdot P L R^{2}
\end{aligned}
$$

These equations are implemented in EnergyPlus tool for the energy performance evaluation of the heat pump. In this study, the coefficients of the equations $\left(A_{i}, B_{i}, C_{i}, D_{i}, a, b, c, d, e, f\right)$ have been calculated according to Tang (2005) using data provided from the manufacturer and they fit the behaviour of the heat pump. Finally, at each time step the energy delivered and the electrical power of the heat pump can be calculated.

\section{CASE STUDY}

The building used as a case study is located in the city of Padova, in the northern part of Italy. It is a four-storey office building with a total floor area of 2,200 $\mathrm{m}^{2}$. Three floors are above ground and one level is underground (Figure 1.a). Approximately 90 people work inside this building. The North and South facades are completely glazed (the south is a double-skin type). The west-side wall is opaque with a large central window on the first two floors, while the top west-side floor is fully glazed. The main characteristics of the building are shown in Table 1 . The construction was completed in 2003 and the whole building has been operational since 2004. A radiant and primary air HVAC system is installed: during the daytime the air handling unit is on, whereas the thermally activated radiant building system is switched on during the night (Currò Dossi et al., 2003).

The heating and cooling demand of the building was originally provided with a double circuit, four compressors R407C water to water heat pump (see Table 2) coupled to 16 borehole heat exchangers, $95 \mathrm{~m}$ long and $7 \mathrm{~m}$ apart and arranged in an L-shape (Figure 1.b). The heat pump is used for both space heating and cooling as well as for the air handling unit; it operates with one temperature setpoint in heating mode, i.e. $35^{\circ} \mathrm{C}$, and with two different setpoints in cooling mode, i.e. $7^{\circ} \mathrm{C}$ and $15^{\circ} \mathrm{C}$ in daytime and night time, respectively, to improve the energy efficiency when no air handling is required. In this case, the supply temperature produced by the heat pump does not depend on the external air temperature in order to simplify the control system.

The borehole heads are buried at about $1 \mathrm{~m}$ beneath the ground surface. Double U-tube heat exchangers are 
installed inside the boreholes and the outside (inside) diameter of the pipe is $32 \mathrm{~mm}(26 \mathrm{~mm})$; the borehole diameter is $140 \mathrm{~mm}$. The two U-tubes inside each borehole heat exchanger are coupled in parallel. The heat-carrier fluid inside the ground heat exchangers is pure water with a total constant mass flow rate equal to $5.56 \mathrm{~kg} / \mathrm{s}$.

Table 1 - Thermal transmittance of the building's envelope.

\begin{tabular}{lc}
\hline & {$\left[\mathbf{W} /\left(\mathbf{m}^{2} \mathbf{K}\right)\right]$} \\
\hline \hline External Wall - West Side & 0.45 \\
\hline Ground Contact Wall & 0.49 \\
\hline External Wall - East Side & 0.18 \\
\hline Roof & 0.57 \\
\hline Ground Contact Floor & 0.33 \\
\hline Glazed Facade - Nord Side & 1.86 \\
\hline Double Skin Facade - South Side & 1.30 \\
\hline Skylight - East Side & 1.45 \\
\hline
\end{tabular}

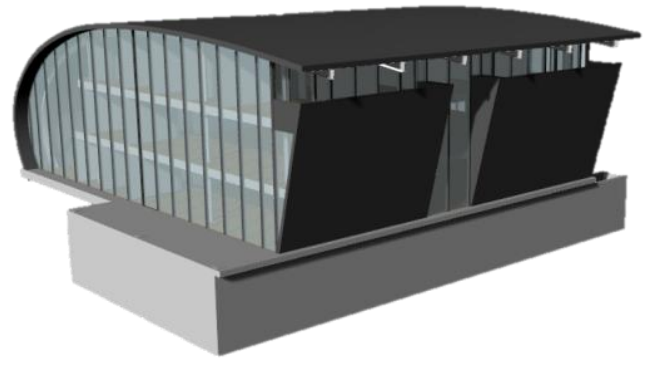

(a)

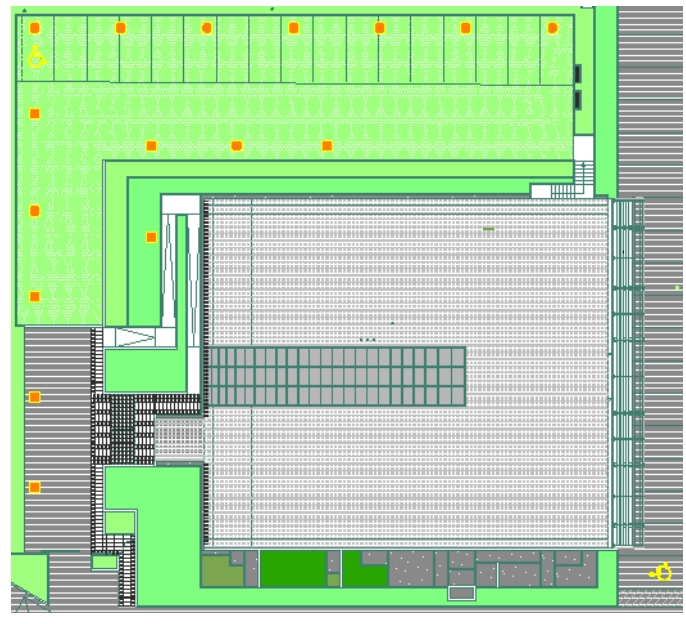

(b)

Figure 1 - North and West view of the building of the EnergyPlus model (a) and plant of the real boreholes field (b).

On the building side, the total mass flow rate of water (i.e. the heat-carrier fluid) is equal to $6.10 \mathrm{~kg} / \mathrm{s}$. The fluid mass flow rates in the loops were considered constant over the simulation time. An equivalent ground layer was used to carry out the simulations: the mean weighted thermal conductivity was $1.9 \mathrm{~W} /(\mathrm{m} \mathrm{K})$ and the volumetric heat capacity was $2.24 \mathrm{MJ} /\left(\mathrm{m}^{3} \mathrm{~K}\right)$. The undisturbed ground temperature was assumed to be $14^{\circ} \mathrm{C}$. The area's groundwater flow effect was considered negligible. The heating and cooling demand of the building was calculated by means of the EnergyPlus tool over eleven years. To this purpose, real weather data provided by the regional environmental agency ARPAV (ARPAV, 2017) for the weather station of Legnaro (at about ten kilometers from the building) were used.

The energy model of EnergyPlus was built dividing the whole building in 59 thermal zones, and for each of them, the geometric and thermal properties of the opaque walls, glazed surfaces, and solar shading surfaces were assigned. Then, for each zone the internal heat gains were set. Figure 2 shows the thermal loads of the heat pump. The ratio between the annual heating and cooling energy demand ranges from 0.56 initially, to 0.4 at the end of the considered period. This confirms that the building's annual load profile is cooling dominant.

As above mentioned an integrated simulation simultaneously considering the building, heat pump and BHEs were implemented in EnergyPlus. For this purpose two blocks were used: one for the water condensing operation and one for the air-condensing operation, together with the pertaining control logic (see Figure 3). In Figure 3.a, in the supply section of the cooling circuit two blocks relative to the different operating conditions (water and air) can be 
seen, while in the lower part (demand section) the two ideal heat exchangers relative to daytime operation (supply to air-handling unit, $7^{\circ} \mathrm{C}$ set-point) and night operation (supply to thermal active building storage, $15^{\circ} \mathrm{C}$ set-point) are shown. In Figure 3.b, the model shows only the geothermal operation, as during the winter the air heat exchanger is not used. Finally, the block concerning the borehole field was implemented using the g-functions calculated via GHLEPRO (Spitler, 2000).

The building is equipped with a BMS (Building Management System) that measures and stores not only the data concerning the control of the HVAC system but also those concerning the overall behaviour of the building-plant system; this was done specifically for research purposes.

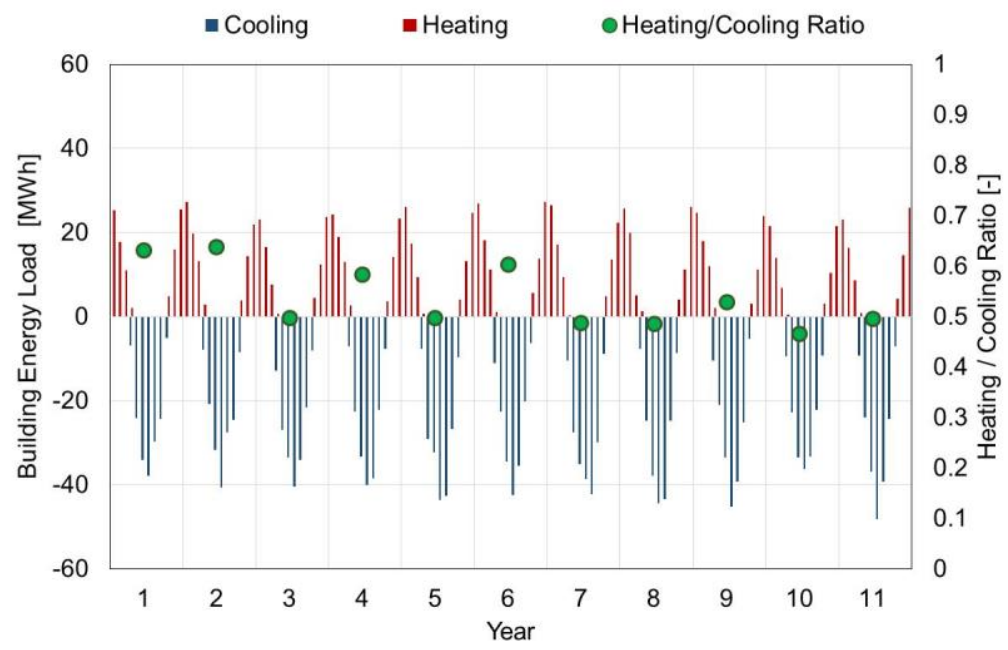

Figure 2 - Synthesis of the building's monthly load profile derived from hourly calculations.

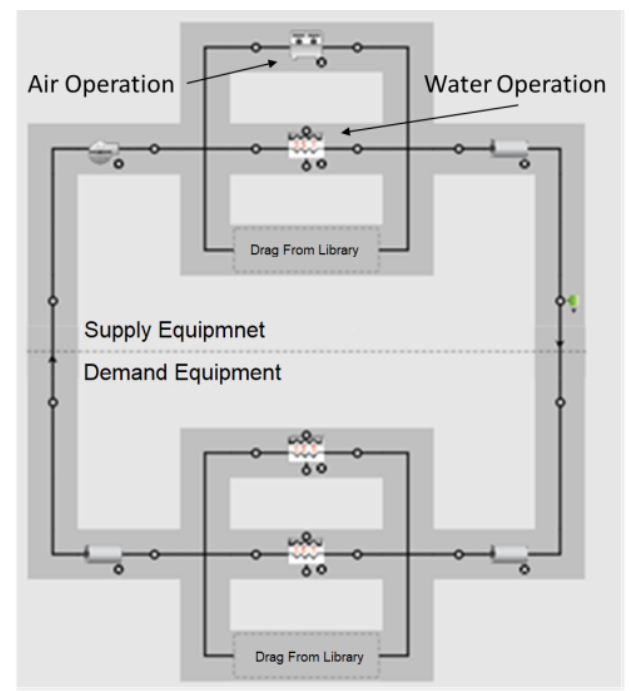

(a)

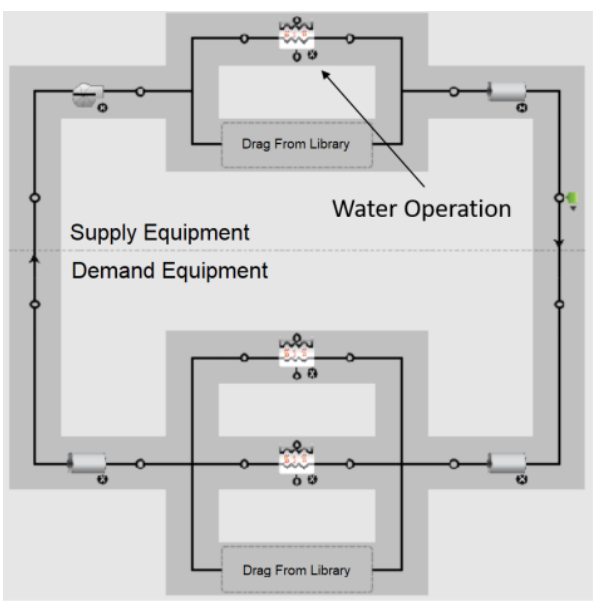

(b)

Figure 3 - Model of the cooling (a) and heating (b) mode of operation of the double source heat pump. 
Table 2 - Characteristics of the old and new heat pump.

\begin{tabular}{|c|c|c|c|}
\hline & \multirow[t]{2}{*}{ OLD } & \multicolumn{2}{|c|}{ NEW } \\
\hline & & AIR & WATER \\
\hline Refrigerant: & $\mathrm{R} 407 \mathrm{C}$ & \multicolumn{2}{|c|}{ R410A } \\
\hline$\left(\mathrm{T}_{\text {fevap: }}: 10 / 7^{\circ} \mathrm{C}, \mathrm{T}_{\text {air }}: 35^{\circ} \mathrm{C}\right), \mathrm{EER}$ & - & $92.6 \mathrm{~kW}, 2.97$ & \\
\hline Cooling Capacity $\left(\mathrm{T}_{\text {fevap }}: 20 / 15^{\circ} \mathrm{C}, \mathrm{T}_{\text {fcond }}: 24 / 30\right)$, EER & $111.9 \mathrm{~kW}, 5.98$ & - & $132,8 \mathrm{~kW}, 5.59$ \\
\hline$\left(\mathrm{T}_{\text {fevap }}: 20 / 15^{\circ} \mathrm{C}, \mathrm{T}_{\text {air }}: 35^{\circ} \mathrm{C}\right), \mathrm{EER}$ & - & $115.4 \mathrm{~kW}, 3.52$ & \\
\hline
\end{tabular}

\section{COMPUTER SIMULATIONS}

The above described model has been applied to simulate the system from year 2005 (date of completion of the building) to year 2026. As for the interval 2006-2017 the real climatic data for the considered location were used, while for the coming years, following the change of the heat pump, the Test Reference Year for the same location was used (see the temperature profile in Figure 4). The results of the simulations have been also compared with the data collected by the monitoring system during the period 2006-2017. In April 2017, the heat pump was changed with a new device and the air-condenser was also installed, consequently the parameters of the new heat pump were implemented. The simulations were carried out without interruptions between the two periods in order to consider the thermal history of the ground due to previous operation through 2006-2017 years.

To analyse the predictable behaviour of the new double source heat pump, different control strategies have been applied to the model, namely different outdoor temperature switch $\left(22^{\circ} \mathrm{C}, 25^{\circ} \mathrm{C}, 28^{\circ} \mathrm{C}\right)$ from air cooled condenser to ground heat exchangers and vice-versa; e.g. when the external air temperature was lower than $22^{\circ} \mathrm{C}$ the air-condenser was switched on, whereas when it was higher than that the condenser of the heat pump was switched on the borehole heat exchangers.

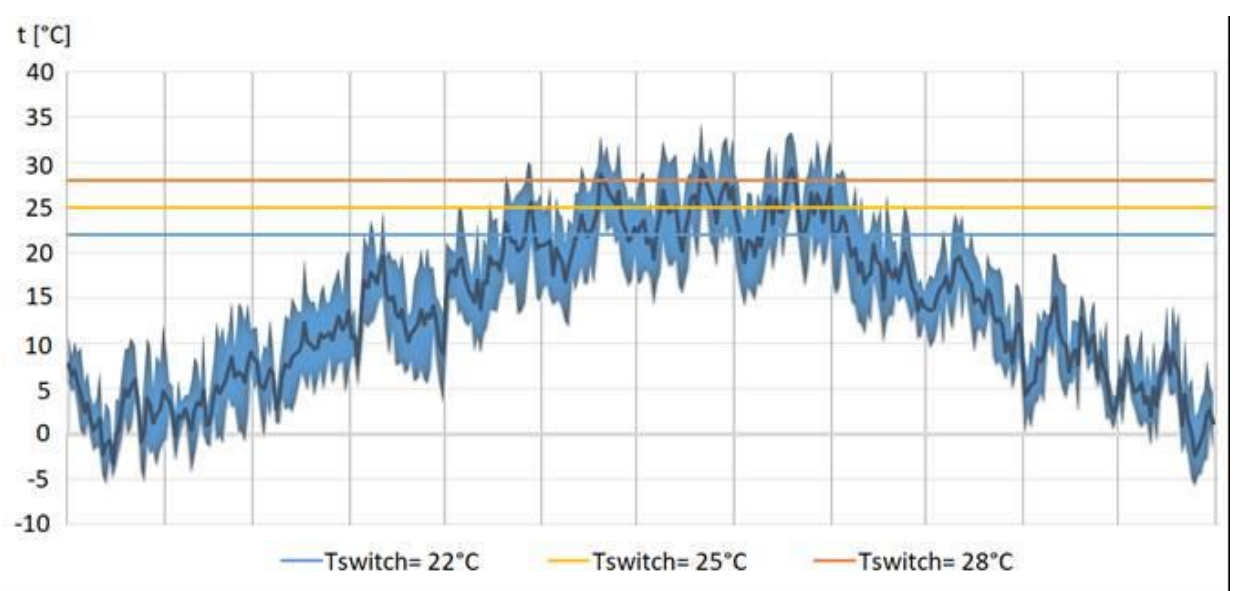

Figure 4 - Temperature profile of the Test Reference Year for Padova (Italy) with highlight of the air temperature switches considered in this work.

\section{RESULTS}

A representational output of the simulations is given in Figure 5 that shows the average monthly fluid temperature leaving the borehole heat exchangers (i.e. entering the heat pump on the ground side). In this figure also the measured values are reported during the years 2006-2017. As can be seen, the simulation results fit satisfactorily 
the measured trend of ground temperature drift throughout the years. As for the prediction of the future trend, the influence of the switch air temperature can be appreciated. If the air-condenser was not installed and the heat pump was not changed, a thermal drift of the ground can be observed considering the weather data of the test reference year. With the new heat pump, when the switch temperature from air to ground decreases the fluid outlet temperature from borehole heat exchangers decreases since the heat load on the ground side decreases. As Figure 5 outlines, the thermal drift of the ground is controlled via air-condenser.

Figure 6 outlines the seasonal energy efficiency of the system taking into account the electrical consumption of the heat pump, ground loop pump and air fans. As the figure shows, the seasonal energy efficiency in heating mode increases whereas that in cooling decreases during 2006-2017 years due to the cooling dominant load profile of the building. With the air-condenser the effect of the thermal drift on the energy efficiency is limited.

Figure 7 shows the electrical consumption of the system. As it can be seen, with the switch temperature equal to $28^{\circ} \mathrm{C}$ from air to ground, the energy consumption is quite the same for air and ground loop; moreover, the total consumption is lower than other cases with switch temperature of 25 and $22^{\circ} \mathrm{C}$. In addition, without the aircondenser, the total energy consumption would be higher than all cases.

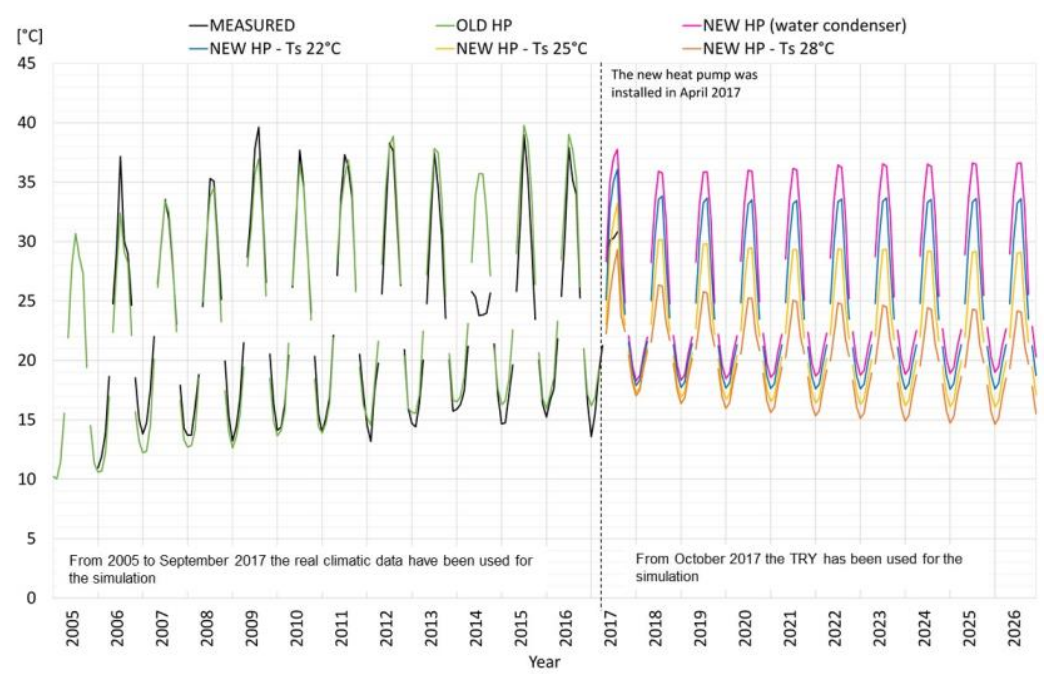

Figure 5 - Profiles of average monthly fluid temperatures leaving the boreholes throughout the simulation period.

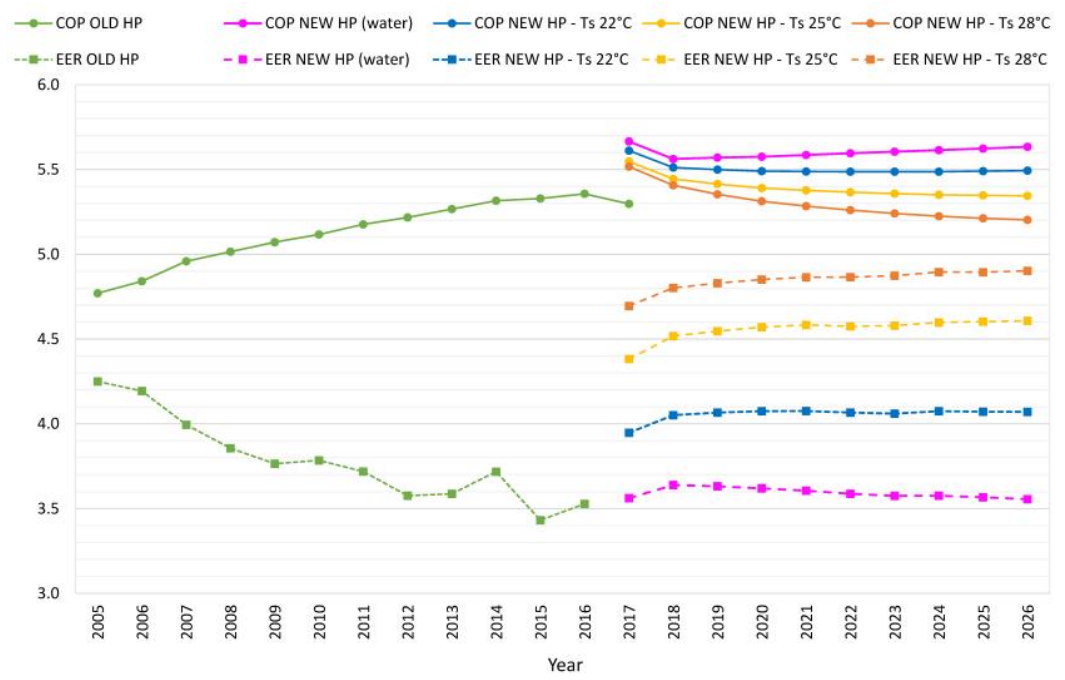

Figure 6 - Profiles of seasonal COP and EER of the heat pump, under different hypotheses of air temperature switch. 


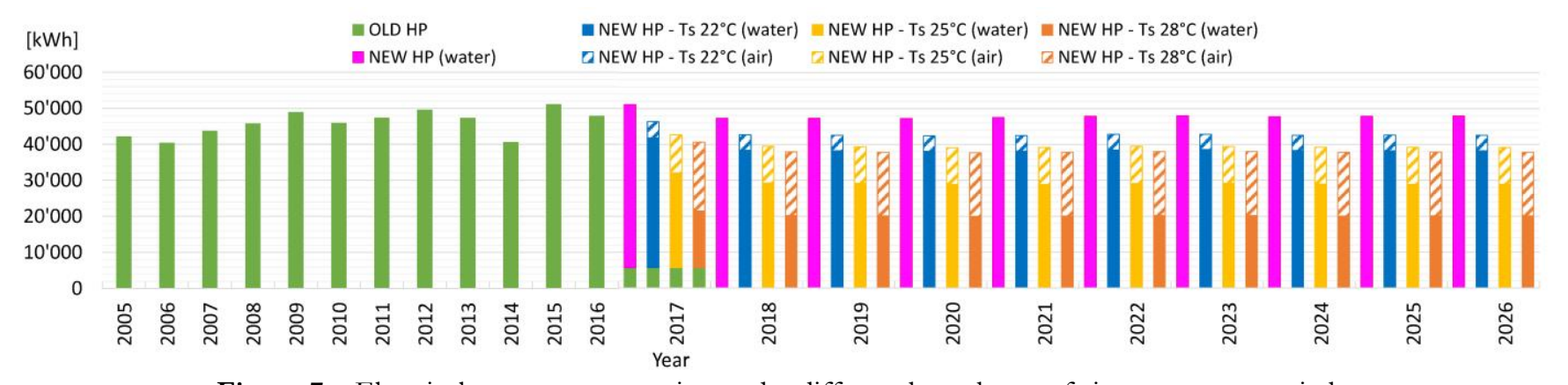

Figure 7 - Electrical energy consumption under different hypotheses of air temperature switch.

\section{CONCLUSIONS}

This study shows that the adoption of air as a secondary source/sink in ground source heat pump systems is suitable to hinder the ground temperature drift which is practically unavoidable when a building exhibits an appreciable unbalance between heating and cooling requirements

The simulations performed demonstrate that a simple control logic as a fixed value of temperature switch between the two condensing media, is good to contrast the temperature drift and improve the energy performance. Moreover, it arises that a relatively high value of switch temperature is sufficient to achieve the above mentioned goals.

\section{ACKNOWLEDGMENTS}

Special thanks are due to HiRef S.p.A. for providing the full set of performance data concerning the heat pump examined in this work.

\section{NOMENCLATURE}

$a=$ Thermal diffusivity $\left(\mathrm{m}^{2} / \mathrm{s}\right)$

$\mathrm{EIR}_{\text {FTemp }}=$ Ratio of electric power and cooling capacity (EIR) as function of leaving chilled fluid temperature and entering condenser air temperature.

$\mathrm{EIR}_{F P L R}=$ Ratio of electric power and cooling capacity (EIR) as function of partial load ratio (PLR).

$\lambda=$ Thermal conductivity $(\mathrm{W} /(\mathrm{m} \mathrm{K}))$

$\mathrm{L}=$ Borehole length $(\mathrm{m})$

PLR $=$ Partial Load Ratio.

Power $_{c}=$ Power in cooling of the heat pump (W)

Power $_{h}=$ Power in heating of the heat pump (W)

$\mathrm{Q}_{c}=$ Heat rate in cooling of the heat pump (W)

$\mathrm{Q}_{h}=$ Heat rate in heating of the heat pump (W)

$q=$ Specific heat load $(\mathrm{W} / \mathrm{m})$

$r=$ Radial distance from the line source $(\mathrm{m})$

$\mathrm{R}_{\mathrm{b}}=$ Borehole thermal resistance $(\mathrm{m} \mathrm{K} / \mathrm{W})$

$\tau=$ Time $(\mathrm{s})$

$\mathrm{T}=$ Temperature $\left({ }^{\circ} \mathrm{C}\right)$

$T_{g}=$ Undisturbed ground temperature $\left({ }^{\circ} \mathrm{C}\right)$

$T_{L, i n}=$ Entering heat pump fluid temperature on the load side $(\mathrm{K})$

$T_{S, i n}=$ Entering heat pump fluid temperature on the source side (K)

$\mathrm{T}_{c f, l}=$ Leaving chiller fluid temperature $\left({ }^{\circ} \mathrm{C}\right)$ 
$\mathrm{T}_{\text {cond }, e}=$ Entering condenser fluid temperature $\left({ }^{\circ} \mathrm{C}\right)$

$\mathrm{V}_{L}=$ Volumetric flow rate on the load side of the heat pump $\left(\mathrm{m}^{3} / \mathrm{s}\right)$

$\mathrm{V}_{s}=$ Volumetric flow rate on the source side of the heat pump $\left(\mathrm{m}^{3} / \mathrm{s}\right)$

$\mathrm{V}_{S, \text { ref }}=$ Reference volumetric flow rate on the source side of the heat pump $\left(\mathrm{m}^{3} / \mathrm{s}\right)$

$\mathrm{V}_{L, \text { ref }}=$ Reference volumetric flow rate on the load side of the heat pump $\left(\mathrm{m}^{3} / \mathrm{s}\right)$

\section{Subscripts}

$$
\begin{aligned}
b & =\text { borehole } \\
\text { cond } & =\text { condenser } \\
f & =\text { fluid } \\
\text { evap } & =\text { evaporator } \\
g & =\text { ground } \\
\text { nom } & =\text { nominal conditions } \\
r e f & =\text { reference } \\
s & =\text { steady state }
\end{aligned}
$$

\section{REFERENCES}

ARPAV Agenzia Regionale per la Prevenzione e per la Protezione Ambientale del Veneto. 2017. http://www.arpa.veneto.it Bayer, P., Saner, D., Bolay, S., Rybach and P. Blum. 2012. Greenhouse gas emission savings of ground source heat pump systems in Europe: a review. Renewable and Sustainable Energy Reviews 16: 1256-1267.

Corberán, J. M., Cazorla-Marin A., Marchante-Avellaneda, J. and C. Montagud. 2018. Dual Source Heat Pump, a High Efficiency and Cost-Effective Alternative for Heating, Cooling and DHW Production. International Journal of Low-Carbon Technologies 13: 161-176.

Currò Dossi, F., De Carli, M., Del Bianco, R., Fellin, F., Tonon, M. and R. Zecchin. 2003. A pilot project for a low energy building equipped with thermal slabs, heat pump and ground heat storage. $8^{\text {th }}$ International IBPSA Conference Eindhoven, Netherlands, August 11-14.

Eskilson, P. 1987. Thermal analysis of heat extraction boreholes. Ph.D. Thesis, Lund University, Department of Mathematical Physics. Lund, Sweden.

GEOT€CH, Geothermal Technology for €conomic Cooling and Heating. (sub-programme H2020-LCE-2014-2, 656889). http://www.geotechproject.eu/ (10 May 2018, date last accessed).

Michopoulos, A., Bozis, D., Kikidis, P., Papakostas, K. and N.A. Kyriakis. 2007. Three-years operation experience of a ground source heat pump system in Northern Greece. Energy and Buildings 39: 328-334.

Ruiz-Calvo, F., Montagud, C., Cazorla-Marín, A. and J.M. Corberán. 2017. Development and Experimental Validation of a TRNSYS Dynamic Tool for Design and Energy Optimization of Ground Source Heat Pump Systems. Energies 10: 1510.

Spitler, J.D. 2000. GLHEPRO a design tool for commercial building ground loop heat exchangers. In: Proceedings of fourth international heat pumps in cold climates conference. Aylmer, Quebec; 17th - 18th August.

Tang, C.C. 2005. Modeling Packaged Heat Pumps in a Quasi-steady State Energy Simulation Program. Oklahoma State University, Stillwater, Oklahoma (US).

U.S. Department Of Energy. 2016. Engineering Reference Manual. In EnergyPlus V8.5. 